\title{
Survival of Vibrio anguillarum, a Fish Pathogen, in Freshwater by Forming Biofilms
}

\author{
ERINA FUJIWARA-NAGATA ${ }^{1}$ and Mitsuru EGUCHI ${ }^{1 *}$ \\ ${ }^{1}$ Department of Fisheries, Faculty of Agriculture, Kinki University, Nara 631-8505, Japan
}

(Received July 16, 2003-Accepted August 21, 2003)

Vibriosis caused by Vibrio anguillarum seriously injures freshwater fish (Salmoniforms) almost every year in Lake Biwa, Japan. This pathogen needs $\mathrm{NaCl}$ for its growth and survival. When the pathogen was directly exposed to sterilized aged lake water (ALW) at room temperature, it suddenly lost its culturability and pathogenicity, and died within half a day due to the low osmolarity. In this report, the survival of the pathogen as biofilms formed on air-solid and liquid-solid (agar or polystyrene) interfaces in ALW was investigated. When the biofilms formed at air-solid and liquid-solid (agar or polystyrene) interfaces were exposed to ALW at $4-5^{\circ} \mathrm{C}$ in the dark, the pathogen survived for more than 2 and 4 weeks, respectively. The biofilms at both interfaces at $4-5^{\circ} \mathrm{C}$ in the dark enhanced the production of a mucous polymer matrix. The main constituent of the polymer was exopolysaccharide. The polymer was produced only in the dark at low temperature. At $20^{\circ} \mathrm{C}$, there was no production of the polymer and the survival of the pathogen was shortened. The biofilm seemed to provide a functional consortium to support the survival of $V$. anguillarum in freshwater.

Key words: Vibrio anguillarum, biofilm, survival, freshwater, fish pathogen

Pathogenic bacteria, once released from their hosts into natural environments, confront various forms of stress such as nutrient starvation, $\mathrm{pH}$ change, osmotic change, temperature variation and oxidative stress. Vibrio anguillarum is a fish pathogen and the causative agent of the most serious disease afflicting salmonid cultures, being active over a range of $\mathrm{Na}^{+}$concentrations encompassing freshwater to seawater. When $V$. anguillarum is released into brackish or marine waters containing a higher $\mathrm{Na}^{+}$concentration than the physiological level, it can maintain its colony forming ability for several months ${ }^{15)}$. However, when $V$. anguillarum is directly exposed to freshwater, it rapidly enters a nonculturable state within half a day at room temperature and does not recover even inside the fish body ${ }^{8,9)}$. This sudden loss of culturability in freshwater is mainly due to the low osmolarity caused by the lack of $\mathrm{Na}^{+8,9,13)}$. The nonculturable $V$. anguillarum in freshwater is considered to be in the process of dying ${ }^{9}$.

\footnotetext{
* Corresponding author; E-mail: eguchi@nara.kindai.ac.jp, Tel: +81-742-43-1511, Fax: +81-742-43-1316
}

Even in freshwater, however, some environmental factors such as low temperature, darkness and microaerobiosis can reduce the stress from which $V$. anguillarum suffers ${ }^{9)}$. In addition to environmental factors, a high cell density also elongated the survival period of $V$. anguillarum in freshwater ${ }^{18)}$. Thus, some combinations of factors enable $V$. anguillarum cells to survive longer without loosing their culturability even in freshwater. The formation of a biofilm is one explanation encompassing all these factors for survival, i.e., darkness, microaerobiosis and high cell density. Actually, in the natural environment, bacteria are often recognized as biofilms ${ }^{19,20)}$. V. anguillarum cells also colonize the fish gastrointestinal tract ${ }^{6}$. Thus, there is a possibility that $V$. anguillarum is introduced into the natural water as a biofilm formed inside infected fish. Furthermore, bacterial cells in biofilms show different genetical and physiological features from bacteria in the free-floating unicellular form $^{20)}$.

In this study, we elucidated the ecological contribution of biofilms to the survival of $V$. anguillarum in freshwater, under conditions where the free-floating unicellular form 
can not survive.

\section{Materials and Methods}

\section{Bacterial strain and pre-culture conditions}

$V$. anguillarum serotype J-O-1 strain M93 was used for survival trials. $V$. anguillarum M93 was originally isolated from diseased fish, Plecoglossus altivelis (Salmoniforms), in Lake Biwa, Japan. This strain causes vibriosis in both freshwater and seawater fish ${ }^{6,17,18)}$. All experiments excluding $\mathrm{C}$ in Fig. 1 were carried out with pre-cultured cells at late log-phase $\left(\mathrm{OD}_{660}=0.8\right)$ in $\mathrm{R}$ medium, a nutrient-rich complex medium ${ }^{18)}$, at $20^{\circ} \mathrm{C}$ in the dark. $\mathrm{R}$ medium contained $3.0 \mathrm{~g}$ of yeast extract (Difco, USA), $5.0 \mathrm{~g}$ of Trypticase peptone (Becton Dickinson, MD, USA), and $7.5 \mathrm{~g}$ of $\mathrm{NaCl}$ per liter of distilled water.

\section{Biofilm formation and survival in $A L W$}

The experimental procedure for evaluating the survival of $V$. anguillarum-biofilms in sterilized aged lake water (ALW) is summarized in Fig. 1. Three different biofilms were prepared for survival trials as follows; A, air-solid (agar): Sterilized membrane filters (Millipore; $\phi 1 \mathrm{~cm}$ ) were placed on R agar plates, and $10 \mu \mathrm{l}$ of pre-cultured $V$. anguillarum was dropped onto the filters. The inoculated filters on the agar plates were incubated at $20^{\circ} \mathrm{C}$ in the dark until the growth of colonies (biofilms) arrested. The arrested colonies were treated as 0-day-old biofilm, and 0-day-old biofilm aged for an additional $x$-days without colony size change was expressed as $x$-day-old biofilm. These arrested colonies were soaked in $6 \mathrm{ml}$ of $\mathrm{ALW}$ at $5^{\circ} \mathrm{C}$ or $20^{\circ} \mathrm{C}$ in light or the dark. For exposure to ALW, 12-well plates (IWAKI, Tokyo, Japan) were used. At appropriate times (day 0-14) after the exposure to ALW, the filters were removed gently and placed onto $\mathrm{R}$ agar plates. Then, the agar plates were incubated for 4 days at $20^{\circ} \mathrm{C}$ in the dark. After the incubation, the filter was judged as survival-positive, when newly formed colonies were recognized. In order to estimate total and viable counts in the biofilm, the filter of 7-day-old biofilm soaked in the ALW for 7 days was vortexed for a few seconds to disperse the cells in the biofilm into the ALW. Then, total and viable counts in the well (6 ml) were enumerated by 4',6-diamidino-2-phenylindole (DAPI) epifluorescence microscopy and R agar plates, re-

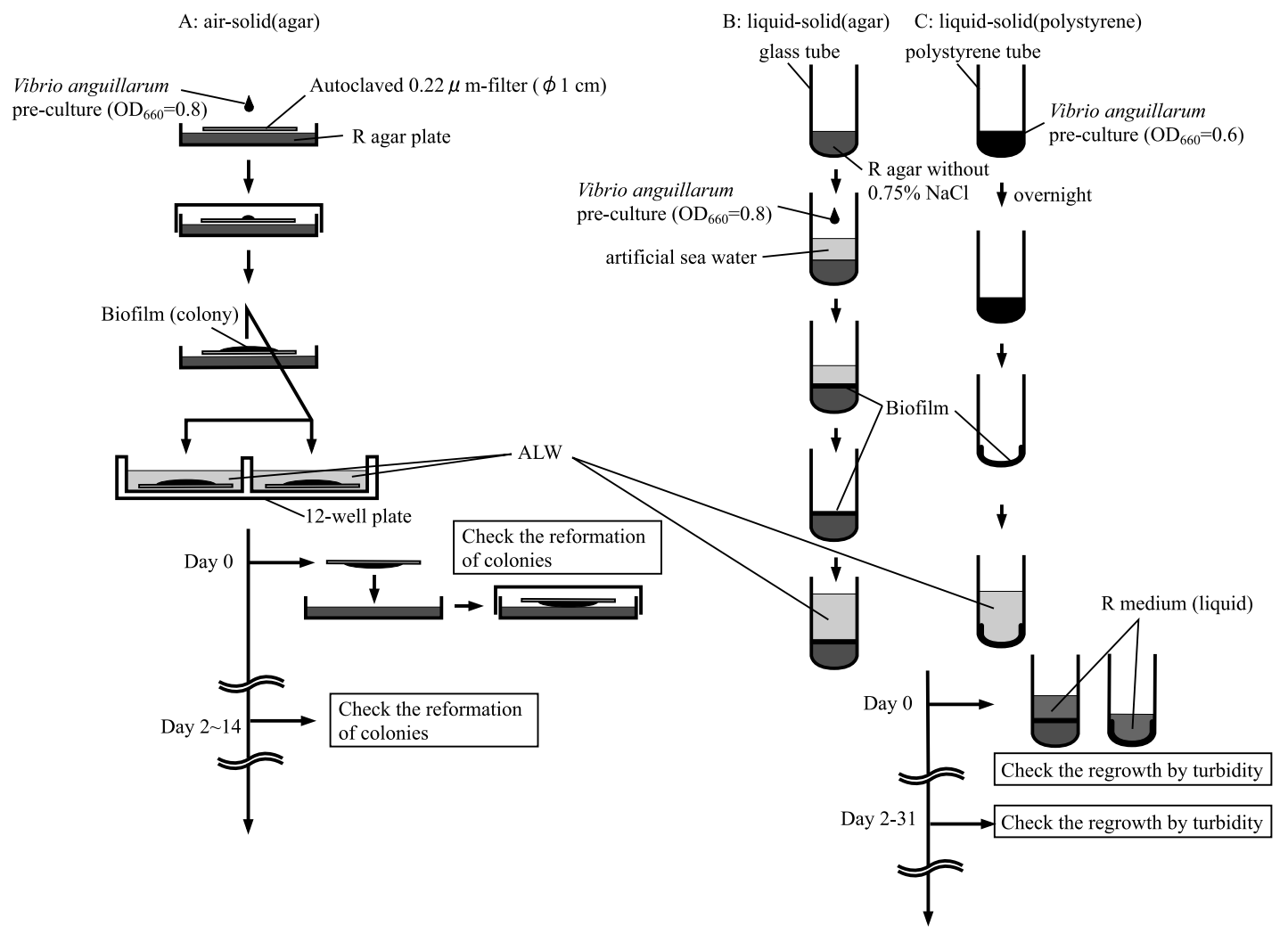

Fig. 1. Scheme for evaluating the survival of V. anguillarum-biofilms in autoclaved aged lake water (ALW). 
spectively. B, liquid-solid (agar): $3 \mathrm{ml}$ of sterilized artificial seawater (NSS, nine salts solution) ${ }^{10)}$ was added to each glass tube containing $3 \mathrm{ml}$ of $\mathrm{R}$ agar without $0.75 \% \mathrm{NaCl}$ in the bottom, and then $10 \mu \mathrm{l}$ of the pre-cultured $V$. anguillarum was inoculated into the seawater. When colonies formed on the agar surface and the growth of the colonies arrested, the seawater in the tubes was removed. The agar surface and tubes were gently rinsed twice with sterilized ALW. Then $10 \mathrm{ml}$ of sterilized ALW was poured into the tubes and the biofilms (colonies) on the agar were exposed to ALW. At appropriate times (day 0-31) during the exposure at $4-5^{\circ} \mathrm{C}$ in the dark, the overlaying ALW was discarded and freshly prepared $\mathrm{R}$ liquid medium was added to the tubes. Then, the tubes were incubated at $20^{\circ} \mathrm{C}$ in the dark. When the liquid medium on the agar became turbid, the biofilm was judged as survival-positive. C, liquid-solid (polystyrene): Sterilized polystyrene tubes (IWAKI, Tokyo, Japan) containing $3 \mathrm{ml}$ of pre-cultured $V$. anguillarum $\left(\mathrm{OD}_{660}=0.6\right.$, mid log phase $)$ were incubated overnight. After the overnight incubation, when the cultures were in the stationary phase, the cultures in the tubes were discarded. The tubes were rinsed twice with sterilized ALW gently. Then, $10 \mathrm{ml}$ of sterilized ALW was added to the tubes, and biofilms formed on the tube surface were exposed to ALW at $4-5^{\circ} \mathrm{C}$ in the dark. At appropriate times (day 0-31) during the exposure to ALW, the biofilm-survival was checked in the same way as for the liquid-solid (agar) case (B in Fig. 1). In order to check the formation of the biofilm on polystyrene tubes (C in Fig. 1), a crystal violet solution was added to the tubes. After $5 \mathrm{~min}$ incubation, the tubes were rinsed with distilled water and filled with dimethyl sulfoxide (DMSO). Then, the amount of crystal violet in the resultant suspension was measured photometrically at a wavelength of $570 \mathrm{~nm}$. We observed biofilm formation in all polystyrene tubes used for the experiment and the biofilm volume did not change throughout the experimental period. In both cases of $\mathrm{B}$ and $\mathrm{C}$ (Fig. 1), 0-day-old biofilms were used. The polymer matrix of biofilms in Fig. 1 was stained with alcian blue. All experiments in Fig. 1 were carried out in triplicate. The ALW used for the experiments was collected from a depth of $50 \mathrm{~m}$ in Lake Biwa, Japan, filtered through a GF/C membrane filter (Whatman, Maidstone, UK) to remove debris and phytoplankton and aged in the dark over 3 months. This ALW was used throughout the study as natural lake water.

\section{Light conditions}

Experiments were performed under light or in the dark (A in Fig. 1). The light was provided by a standard cool-white fluorescent lamp (FL20SSECW18, white type, Matsushita Electric Industrial Co., Ltd., Kadoma, Japan) with a 14hlight/10h-dark photo-cycle.

\section{Cell morphology}

Morphological changes to the cells in R liquid medium, ALW and biofilms exposed to ALW were observed using an epifluorescence microscope with DAPI staining.

\section{Results}

\section{Survival of V. anguillarum-biofilms in $A L W$}

Variously aged biofilms at the air-solid interface (A in Fig. 1) were exposed to $\mathrm{ALW}$ at $20^{\circ} \mathrm{C}$ in the dark (Table 1). Under these conditions $\left(20^{\circ} \mathrm{C}\right.$, dark $), 3$ and 7-day-old biofilms survived for one and two days in ALW, respectively. Other biofilms lost their culturability within one day. In contrast, at a lower temperature $\left(5^{\circ} \mathrm{C}\right)$ in the dark, the biofilms survived longer, at least 4 days (Table 2). The 7-dayold biofilm showed the best survival, maintaining its culturability for at least 14 days. Three and 10-day-old biofilms

Table 1. Survival of $V$. anguillarum-biofilms at the air-solid interface in autoclaved aged lake water (ALW). Biofilms (colonies) were formed at $20^{\circ} \mathrm{C}$ in the dark and exposed to $\mathrm{ALW}$ after appropriate aging $(0-14$ days $)$ at $20^{\circ} \mathrm{C}$ in the dark.

\begin{tabular}{cccccc}
\hline \multirow{2}{*}{ Aging of biofilms* } & & & Exposure time to ALW & & \\
\cline { 2 - 6 } & Day-1 & Day-2 & Day-3 & Day-4 & Day-5 \\
\hline 0-day-old & $\times$ & $\times$ & $\times$ & $\times$ & $\times$ \\
3-day-old & $\bigcirc$ & $\times$ & $\times$ & $\times$ & $\times$ \\
7-day-old & & & $\times$ & $\times$ & $\times$ \\
10-day-old & $\times$ & $\times$ & $\times$ & $\times$ & $\times$ \\
14-day-old & $\times$ & $\times$ & $\times$ & $\times$ & $\times$ \\
\hline
\end{tabular}

, colonies were successfully reformed; $X$, no colony-reformation. ${ }^{*}$, the time after visible colonies stopped enlarging on the filters placed on agar plates. 
Table 2. Survival of $V$. anguillarum-biofilms at the air-solid interface in autoclaved aged lake water (ALW). Biofilms (colonies) were formed and aged at $20^{\circ} \mathrm{C}$ in the dark and exposed to $\mathrm{ALW}$ at $5^{\circ} \mathrm{C}$ in the dark.

\begin{tabular}{|c|c|c|c|c|c|c|c|}
\hline \multirow{2}{*}{ Aging* of biofilms } & \multicolumn{7}{|c|}{ Exposure time to ALW } \\
\hline & Day-5 & Day-6 & Day-7 & Day-8 & Day-10 & Day-11 & Day-14 \\
\hline 0-day-old & O & $x$ & $x$ & $x$ & $x$ & $x$ & $x$ \\
\hline 3-day-old & $\bigcirc$ & $\bigcirc$ & $\bigcirc$ & $\bigcirc$ & $\bigcirc$ & $x$ & $x$ \\
\hline 7-day-old & $\bigcirc$ & $\bigcirc$ & $\bigcirc$ & $\bigcirc$ & $\bigcirc$ & $\bigcirc$ & $\bigcirc$ \\
\hline 10-day-old & $\bigcirc$ & $\bigcirc$ & $\bigcirc$ & $\bigcirc$ & $\bigcirc$ & $x$ & $x$ \\
\hline 14-day-old & $\bigcirc$ & $\bigcirc$ & 0 & $\bigcirc$ & $x$ & $x$ & $x$ \\
\hline 17-day-old & 0 & ○ & $x$ & $x$ & $x$ & $x$ & $x$ \\
\hline 21-day-old & 0 & $x$ & $x$ & $x$ & $x$ & $x$ & $x$ \\
\hline
\end{tabular}

, colonies were successfully reformed; $X$, no colony-reformation. ${ }^{*}$, the time after visible colonies stopped enlarging on the filters placed on agar plates.
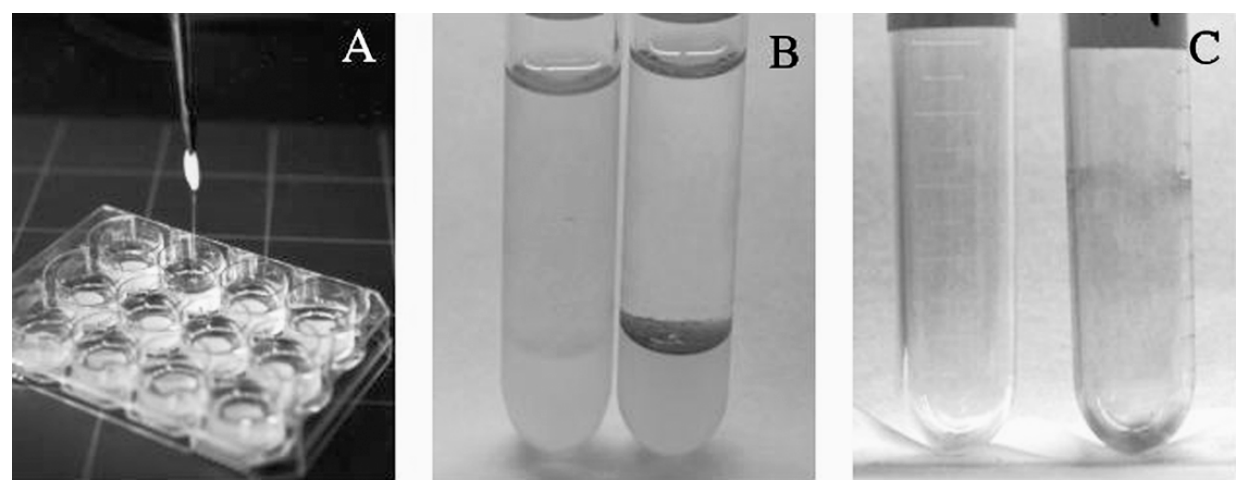

Fig. 2. Photographs of biofilms. A, the polymer matrix which was produced by $V$. anguillarum exposed to ALW at $5^{\circ} \mathrm{C}$ in the dark for 1 week; $\mathrm{B}, 0$-day-old biofilm exposed to $\mathrm{ALW}$ at $4-5^{\circ} \mathrm{C}$ in the dark for 7 days was stained with alcian blue (right-hand tube); C, 0-day-old biofilm exposed to ALW for 7 days at $4-5^{\circ} \mathrm{C}$ in the dark was stained with crystal violet (right-hand tube). Tubes on the left in $\mathrm{B}$ and $\mathrm{C}$ are controls.

survived for 10 days, and 14 and 17-day-old biofilms survived for 8 and 6 days, respectively. The oldest colony, the 21-day-old biofilm, survived for 5 days. Even 0-day-old biofilm, which lost its culturability within one day at $20^{\circ} \mathrm{C}$ in the dark, survived for 5 days at $5^{\circ} \mathrm{C}$ in the dark.

When the filters exposed to ALW were lifted by tweezers, a transparent mucous polymer was observed in all wells with the aged biofilms at $5^{\circ} \mathrm{C}$ in the dark (Fig. 2A). This polymer was not observed clearly in the wells at $20^{\circ} \mathrm{C}$.

To our surprise, 0-day-old biofilms at liquid-solid (agar, Fig. 2B) and liquid-solid (polystyrene, Fig. 2C) interfaces retained their culturability (turbidity in the new media) even after a one-month-exposure to ALW. Production of the polymer was also observed in the biofilms at liquid-solid (agar and polystyrene) interfaces at $4-5^{\circ} \mathrm{C}$ in the dark (Fig. 2B and C).

\section{Effect of light on the survival of $\mathrm{V}$. anguillarum-biofilms}

Using the 7-day-old biofilms, which showed the best survival at the air-solid interface (Table 2), the effect of coolwhite fluorescent light was examined at $5^{\circ} \mathrm{C}$. Transparent 12-well plates, where the biofilms were soaked in ALW, were kept under a $14 \mathrm{~h}-\mathrm{L} / 10 \mathrm{~h}-\mathrm{D}$ photo-cycle at $5^{\circ} \mathrm{C}$ (Table 3). Under these conditions, the survival period was one third of that in the dark at $5^{\circ} \mathrm{C}$, and the amount of polymer produced from the biofilm was far less than that in the dark.

\section{Direct and viable counts in $\mathrm{V}$. anguillarum-biofilms}

Direct and viable counts of 7-day-old biofilm were $2.7 \pm 0.4 \times 10^{10}$ cells $/ 6 \mathrm{ml}$-well and $3.1 \pm 1.0 \times 10^{7} \mathrm{CFU} / 6 \mathrm{ml}-$ well, respectively. The percentage of culturable cells was $0.12 \%$. The average diameter of colonies on the filters was $6.5 \mathrm{~mm}$ and the depth of the colonies was $100-200 \mu \mathrm{m}$. 
Table 3. Effect of light on the survival of $V$. anguillarum-biofilms at the air-solid interface, which were aged for 7 days at $20^{\circ} \mathrm{C}$ in the dark, in sterilized aged lake water $(\mathrm{ALW})$ at $5^{\circ} \mathrm{C}$.

\begin{tabular}{cccccccc}
\hline \multirow{2}{*}{ Light conditions } & \multicolumn{7}{c}{ Exposure time to ALW } \\
\cline { 2 - 7 } & Day-4 & Day-5 & Day-6 & Day-7 & Day-8 & Day-10 & Day-14 \\
\hline Light* & 0 & 0 & $\times$ & $\times$ & $\times$ & $\times$ & $\times$ \\
Dark & 0 & 0 & 0 & 0 & $\bigcirc$ & $\bigcirc$ & $\bigcirc$ \\
\hline
\end{tabular}

$\bigcirc$, colonies were successfully reformed; $X$, no colony-reformation. *, light was provided by a standard cool-white fluorescent lamp with a $14 \mathrm{~h}$ light/10h-dark photo-cycle.
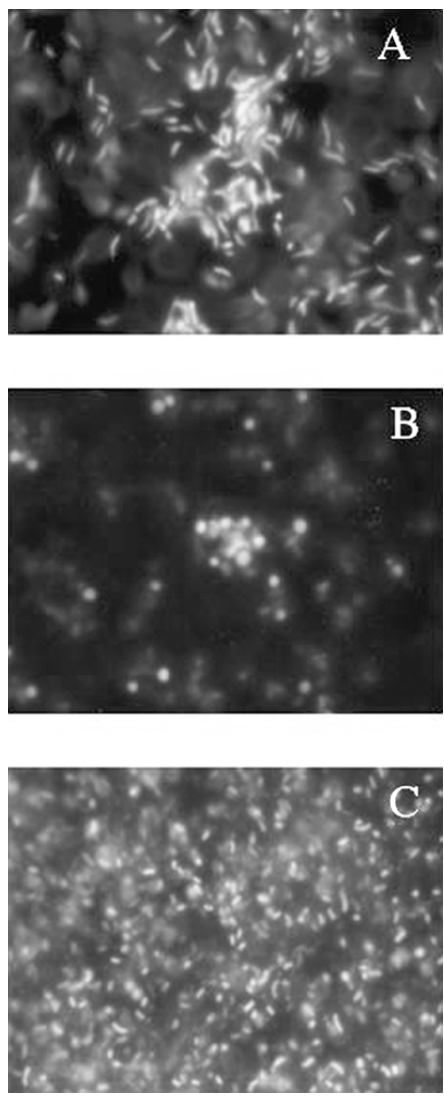

Fig. 3. Photographs of $V$. anguillarum cells. A, growing cells in $\mathrm{R}$ liquid medium; B, cells suspended in ALW for one day; C, cells in 7-day-old biofilm exposed to ALW for one week.

Thus, the cell density of the biofilm was around $3-7 \times 10^{11}$ cells $/ \mathrm{cm}^{3}$.

\section{Morphological features of $\mathrm{V}$. anguillarum in $A L W$}

Cell shapes of $V$. anguillarum were observed by epifluorescence microscopy with DAPI staining (Fig. 3). Fig. 3A shows actively growing cells in $\mathrm{R}$ liquid medium. These cells were relatively rod-like showing typical Vibrio shapes. Floating single cells directly exposed to ALW for one day were swollen and coccoid (Fig. 3B). Cells in the biofilm, which were exposed to ALW for one week at $5^{\circ} \mathrm{C}$ in the dark, showed a different shape from the two types mentioned above; cells embedded in the polymer matrix resembled short rods (Fig. 3C).

\section{Discussion}

A biofilm is defined as "a community of microbes embedded in an organic polymer matrix, adhering to a surface" ${ }^{2}$. As the physical and chemical conditions inside the biofilm are completely different from those facing free-floating unicellular bacteria in surrounding waters ${ }^{5}$, it can be concluded that $V$. anguillarum in biofilm would show unique survival responses. Actually, in this study, the biofilm of $V$. anguillarum showed a 5-10 times longer survival-period in ALW than free-floating cells ${ }^{9}$.

Organic polymer matrix is one of the most important ingredients of a biofilm ${ }^{7}$. We also observed the production of a mucous polymer matrix from $V$. anguillarum, especially in the dark and cold (Fig. 2). As the polymer of $V$. anguillarum was clearly stained by alcian blue (Fig. 2B), exopolysaccharide was the major component of this matrix. The polymer matrix of biofilm has several beneficial functions for bacterial survival in the natural environment ${ }^{5}$ ). For example, it protects bacterial cells from external predation ${ }^{3)}$ and inhibits penetration by antibiotics ${ }^{7,16}$. The polymer matrix is predominantly negatively charged and creates an efficient scavenging system for trapping and concentrating essential minerals such as $\mathrm{Mg}^{2+}$ and $\mathrm{Ca}^{2+}$ and nutrients from the surrounding environment ${ }^{7}$. As the addition of a small amount of divalent cations such as $\mathrm{Mg}^{2+}$ and $\mathrm{Ca}^{2+}$ relieved the steep decline in the survival curve of $V$. anguillarum in freshwater ${ }^{18}$, such an accumulation of divalent cations in the matrix may have helped $V$. anguillarum to survive longer.

In addition to exopolysaccharide, other organic substances might originate from the cell-lysis occurring inside 
the biofilm. This would also be helpful to other cells. However, the cell-dynamics of lysis and regrowth inside the biofilm was not evaluated in this study. Studies are underway to clarify this point using a confocal scanning laser microscope and $V$. anguillarum cells expressing green fluorescent protein.

The aging of the biofilm is also important to the survival period of $V$. anguillarum in freshwater (Table 2). In the case of Staphylococcus aureus, 13-day-old biofilm was more resistant to antibiotics such as tobramycin and cephalexin than 4-day-old biofilm ${ }^{1}$. Although aging was also important for stress-resistance, there seemed to be an optimum period in our study (Table 2). We found out that 7-day-old biofilm of $V$. anguillarum was most resistant to low osmolarity, and further aging weakened the biofilms. Aging might exhaust energy sources and the polymer matrix, and also accumulate toxic by-products inside biofilms ${ }^{7}$.

In the case of 7-day-old biofilm exposed to ALW for 7 days, the percentage of culturable cells $\left(3-7 \times 10^{11}\right.$ cells $\left./ \mathrm{cm}^{3}\right)$ was only $0.12 \%$. However, as we had to disperse the cells into the overlaying ALW to determine cell density, the cells in the biofilm were directly exposed to ALW during this process. Thus, $0.12 \%$ is probably an underestimated value.

Light shortened the survival period of the biofilm of $V$. anguillarum in freshwater (Table 3). The 12-well plates used in the present study were made of transparent polystyrene and the light used was a standard laboratory coolwhite fluorescent lamp. According to the information provided by the manufacturer (IWAKI, Tokyo, Japan), the percentage of UV-visible light transmitted through the polystyrene is $40 \%$ at $300 \mathrm{~nm}$ and $80 \%$ at $\geqq 400 \mathrm{~nm}$. Thus, there is a possibility that weak UV light in the cool-white fluorescent lamp reached the biofilms through the polystyrene well and ALW, and caused some damage to the cells. Actually, Gong et al. measured UV from a standard cool-white lamp and pointed out that the extremely weak UV emission acted as an oxidative stress to starved marine Vibrio $^{14)}$. Visible light could also injure cells by enhancing the production of reactive oxygen species (ROS) inside them ${ }^{12}$. Even though the oxygen concentration was lower inside the biofilm than in the surrounding water ${ }^{4}$, photo-oxidation probably generated some ROS within the biofilm.

The short-rod shaped cells embedded in the polymer matrix at $5{ }^{\circ} \mathrm{C}$ in the dark (Fig. 3C) were extremely similar to those observed in natural bottom sediments in Lake Biwa, Japan using an indirect epifluorescence antibody technique ${ }^{17)}$. Furthermore, the bottom sediment of the lake was also cold, around $6^{\circ} \mathrm{C}$, and dark throughout the year ${ }^{11)}$. This resemblance in terms of shape suggests that the cells deposited on the bottom of the lake were in a similar physiological state to the cells inside the biofilm formed at $5^{\circ} \mathrm{C}$ in the dark.

As $V$. anguillarum is a fish pathogen and vibriosis occurs in regions with water, attachment to a liquid-solid interface such as the body of a fish and grains of sand might be more common for the pathogen than that to an air-solid interface. Thus, we investigated survival patterns of $V$. anguillarumbiofilms formed at liquid-solid interfaces. Even after one month of exposure to ALW, the $V$. anguillarum-biofilms formed at the liquid-solid interfaces survived without loosing their culturability.

In conclusion, the present study showed the possibility that, even in freshwater, $V$. anguillarum can survive without loosing its culturability and pathogenicity by forming biofilms. The biofilm provides a functional consortium to support the survival of $V$. anguillarum in freshwater.

\section{Acknowledgements}

We are grateful to Y. Eguchi, T. Takeda, D.R. Nelson and R. Cavicchioli for their valuable comments on the earlier version of the manuscript. We also thank Y. Suzuki, the late M. Mori, T. Fukao and Y. Takamiya for their technical assistance. This work was partly supported by funds from JSPS (grant no. 10660191) and a Grant-in-Aid for The 21st Century COE program, Japan.

\section{References}

1) Anwar, H., J.L. Strap and J.W. Costerton. 1992. Eradication of biofilm cells of Staphylococcus aureus with tobramycin and cephalexin. Can. J. Microbiol. 38: 618-625.

2) Carpentier, B. and O. Cerf. 1993. Biofilms and their consequences, with particular reference to hygiene in the food industry. J. Appl. Bacteriol. 75: 499-511.

3) Costerton, J.W. and H.M. Lappin-Scott. 1995a. Introduction to microbial biofilms, p. 1-11. In H.M. Lappin-Scott and J.W. Costerton (ed.), Microbial biofilms, 1st ed. Cambridge University Press, N.Y.

4) Costerton, J.W., Z. Lewandowski, D.E. Caldwell, D.R. Korber and H.M. Lappin-Scott. 1995b. Micobial biofilms. Annu. Rev. Microbiol. 49: 711-745.

5) Davey, M.E. and G.A. O'Toole. 2000. Microbial biofilms: from ecology to molecular genetics. Microbiol. Mol. Biol. Rev. 64: 847-867.

6) Denkin, S.M. and D.R. Nelson. 1999. Induction of protease activity in Vibrio anguillarum by gastrointestinal mucus. Appl. Environ. Microbiol. 65: 3555-3560.

7) Dunne, W.M., Jr. 2002. Bacterial adhesion: seen any good biofilms lately? Clinic. Microbiol. Rev. 15: 155-166.

8) Eguchi, M., E. Fujiwara and N. Miyamoto. 2000. Survival of Vibrio anguillarum in freshwater environments: adaptation or 
debilitation? J. Infect. Chemother. 6: 126-129.

9) Eguchi, M., E. Fujiwara-Nagata and N. Miyamoto. 2003. Physiological state of Vibrio anguillarum, a fish pathogen, under starved and low-osmotic environments. Microbes Environ. 18, 160-166.

10) Eguchi, M., T. Nishikawa, K. MacDonald, R. Cavicchioli, J.C. Gottschal and S. Kjelleberg. 1996. Responses to stress and nutrient availability by the marine ultramicrobacterium Sphingomonas sp. strain RB2256. Appl. Environ. Microbiol. 62: 1287-1294.

11) Eguchi, M., T. Oketa, N. Miyamoto, H. Maeda and A. Kawai. 1996. Occurrence of viable photoautotrophic picoplankton in the aphotic zone of Lake Biwa, Japan. J. Plankton Res. 18: 539-550.

12) Eisenstark, A. 1989. Bacterial genes involved in response to nearultraviolet radiation. Adv. Genet. 26: 99-147.

13) Fujiwara-Nagata, E., K. Kogure, K. Kita-Tsukamoto, M. Wada and M. Eguchi. 2003. Characteristics of $\mathrm{Na}^{+}$-dependent respiratory chain in Vibrio anguillarum, a fish pathogen, in comparison with other marine Vibrios. FEMS Microbiol. Ecol. 44: 225-230.

14) Gong, L., K. Takayama and S. Kjelleberg. 2002. Role of spoT- dependent ppGpp accumulation in the survival of light-exposed starved bacteria. Microbiology. 148: 559-570.

15) Hoff, K.A. 1989. Survival of Vibrio anguillarum and Vibrio salmonicida at different salinities. Appl. Environ. Microbiol. 55: 1775-1786.

16) Lewis, K. 2001. Riddle of biofilm resistance. Antimicrobe. Agents. Chemother. 45: 999-1007.

17) Miyamoto, N. and M. Eguchi. 1997a. Direct detection of a fish pathogen, Vibrio anguillarum serotype J-O-1, in freshwater by fluorescent antibody technique. Fish. Sci. 63: 253-257.

18) Miyamoto, N. and M. Eguchi. 1997b. Response to low osmotic stress in a fish pathogen, Vibrio anguillarum. FEMS Microbiol. Ecol. 22: 225-231.

19) O'Toole, G.A. 2002. Microbiology: A resistance switch. Nature. 416: 695-695.

20) Schembri, M.A., K. Kjærgaard and P. Klemm. 2003. Global gene expression in Escherichia coli biofilms. Mol. Microbiol. 48: 253267. 